\title{
Lung cancer: current therapies and new targeted treatments
}

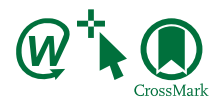

Fred R Hirsch, Giorgio V Scagliotti, James L Mulshine, Regina Kwon, Walter J Curran, Yi-Long Wu, Luis Paz-Ares

Lung cancer is the most frequent cause of cancer-related deaths worldwide. Every year, 1.8 million people are diagnosed with lung cancer, and 1.6 million people die as a result of the disease. 5-year survival rates vary from 4-17\% depending on stage and regional differences. In this Seminar, we discuss existing treatment for patients with lung cancer and the promise of precision medicine, with special emphasis on new targeted therapies. Some subgroups, eg-patients with poor performance status and elderly patients-are not specifically addressed, because these groups require special treatment considerations and no frameworks have been established in terms of new targeted therapies. We discuss prevention and early detection of lung cancer with an emphasis on lung cancer screening. Although we acknowledge the importance of smoking prevention and cessation, this is a large topic beyond the scope of this Seminar.

\section{Introduction}

Every year, 1.8 million people are diagnosed with lung cancer and 1.6 million die of the disease. ${ }^{1} 5$-year survival in populations with lung cancer varies from 4-17\% depending on stage and regional differences. ${ }^{2}$ Much progress has been made in research, lung cancer screening, and personalised therapy (precision medicine) in recent years.

\section{Early lung cancer detection using spiral CT}

The National Lung Screening Trial (NLST) ${ }^{3}$ enrolled 53000 individuals aged 55-74 years with a 30-pack-year smoking history. Participants were randomly assigned to radiography or low-dose $\mathrm{CT}$ and screened at baseline with two annual follow-up scans. Maximum follow-up lasted for 7 years. The low-dose CT group had a $20 \%$ reduction in lung cancer mortality and a $6 \cdot 7 \%$ reduction in all-cause mortality. ${ }^{3}$ The high rates of false-positive findings $(27 \%$ at baseline, $28 \%$ at 1-year follow-up, $16.6 \%$ at 2 -year follow-up) were concerning (table 1$).^{3}$

The International Early Lung Cancer Action Program retrospectively analysed the outcomes of more than 21000 prospectively enrolled patients who underwent lung cancer screening after the completion of the NLST. ${ }^{6}$ Different size thresholds for nodule diameter resulted in different cancer diagnosis rates. Increasing the threshold from $5 \cdot 0 \mathrm{~mm}$ to $6 \cdot 0,7 \cdot 0,8 \cdot 0$, or $9 \cdot 0 \mathrm{~mm}$ also changed the frequencies of positive results. Depending on where the size threshold was reset from $5.0 \mathrm{~mm}$, the diagnostic work-up frequency could be reduced by $36 \%$ for $6.0 \mathrm{~mm}$, $56 \%$ for $7.0 \mathrm{~mm}, 68 \%$ for $8.0 \mathrm{~mm}$, or $75 \%$ for $9.0 \mathrm{~mm}$. With annual screening, the resultant delay in eventual diagnosis was not associated with a reduction in curativeintent surgery. ${ }^{6}$

In NELSON, ${ }^{4}$ a Dutch and Belgian randomised screening trial, a two-part criterion for potential cancer was tested using analysis of the diameter change of a nodule. Of the 7155 prospective participants in the CT screening group, the sensitivity of CT screening was $92.4 \%$ and the specificity was $90 \cdot 0 \%$, which suggests that efficient case detection was feasible. In the UK Lung Cancer Screening Trial, ${ }^{5}$ for the 2028 patients randomly assigned to CT screening, 536 patients had nodules greater than $5 \mathrm{~mm}$ in diameter, and 41 of the 536 patients had lung cancer. The false-positive rate was reported to be $3 \cdot 6 \% .^{5}$
The American College of Radiology (ACR) proposed Lung-RADS, a classification system similar to the system that the ACR use for breast cancer screening, in order to standardise the routine clinical management of lung cancer detection. ${ }^{7}$ When this approach was retrospectively applied to the NLST data, they revealed a proportion of false-positive results at baseline of $12 \cdot 8 \%$, in contrast to $26.6 \%$ reported by the NLST. ${ }^{8}$ The corresponding falsepositive proportion after baseline was $5 \cdot 5 \%$ for LungRADS, versus $21.8 \%$ for NLST. ${ }^{8}$ These efforts suggest lung cancer screening management can be delivered with greater efficiency than the approach used 10 years ago in the NLST. ${ }^{3}$

Other changing aspects of CT screening include the use of lower medical radiation doses for imaging.' Updates to the international lung cancer pathology classification have improved delineation of the types of lung processes associated with invasive versus benign clinical behaviour. ${ }^{10}$ A review ${ }^{11}$ of the outcomes of 57496 international screening cases substantiated the indolent behaviour of non-solid pulmonary nodules, and suggests that, in this setting, a more conservative approach to surgical resection is appropriate. This finding complements a number of reports about better management of screen-detected lung cancer and reducing the potential for surgical overtreatment. ${ }^{12,13}$

The UK Lung Cancer Screening Trial ${ }^{5}$ reported the cost-effectiveness of one-time screening was $£ 8466$ per quality-adjusted life-year. This is similar to the robust actuarial cost projection for lung cancer screening in the USA. $^{14}$ Inclusion of best-practice tobacco cessation

Search strategy and selection criteria

We did our primary search from Nov 1,2015 , to Jan 31, 2016, with continuous monitoring of the literature until June 30, 2016. Searches were done in PubMed in English using the phrase "lung cancer" in combination with "early stage", "advanced stage", "targeted therapy", and "immunotherapy". Relevant studies were chosen based on the expertise of the co-authors. Additional reports were taken from international conferences in the USA, Europe, and Asia.
Lancet 2017; 389: 299-311

Published Online August 26, 2016 http://dx.doi.org/10.1016/ S0140-6736(16)30958-8

Department of Medicine, Division of Medical Oncology and Department of Pathology University of Colorado Cancer Center, Denver, CO, USA (Prof F R Hirsch MD); International Association for the Study of Lung Cancer, Aurora, CO, USA (Prof F R Hirsch); Division of Oncology, Department of Oncology, San Luigi HospitalOrbassano, University of Torino, Orbassano, Italy (Prof G V Scagliotti MD); Rush University Medical Center, Chicago, IL, USA

(Prof J L Mulshine MD); School of Medicine, University of Colorado, Denver, CO, USA (R Kwon BA); Department of Radiation Oncology and Winship Cancer Institute, Emory University, Atlanta, GA USA (Prof WJ Curran Jr MD); Guangdong Lung Cancer Institute, Guangdong General Hospital and Guangdong Academy of Medical Sciences, Guangzhou, Guangdong, China (ProfY-L Wu MD); and Medical Oncology Department, Hospital Universitario Doce de Octubre and CNIO, Madrid, Spain (Prof L Paz-Ares MD) Correspondence to: Prof Fred R Hirsch, Department of Medicine, University of Colorado, Anschutz Medical Campus, Aurora, CO 80045, USA fred.hirsch@ucdenver.edu 


\begin{tabular}{|c|c|c|c|c|c|c|c|}
\hline & \multirow{2}{*}{$\begin{array}{l}\text { Stage I } \\
(\%)^{*}\end{array}$} & \multicolumn{3}{|l|}{ Round 1} & \multicolumn{3}{|l|}{ Round 2} \\
\hline & & $\begin{array}{l}\text { Total } \\
\text { patients } \\
\text { screened } \\
\text { (n) }\end{array}$ & $\begin{array}{l}\text { Cancer } \\
\text { diagnoses } \\
\text { (n) }\end{array}$ & $\begin{array}{l}\text { Proportion } \\
\text { of patients } \\
\text { diagnosed } \\
\text { with cancer } \\
(\%)\end{array}$ & $\begin{array}{l}\text { Total patients } \\
\text { screened }(n)\end{array}$ & $\begin{array}{l}\text { Cancer } \\
\text { diagnoses } \\
\text { (n) }\end{array}$ & $\begin{array}{l}\text { Proportion } \\
\text { of patients } \\
\text { diagnosed } \\
\text { with cancer } \\
(\%)\end{array}$ \\
\hline $\begin{array}{l}\text { National Lung } \\
\text { Screening Trial }\end{array}$ & 66 & 24715 & 168 & 0.67 & 24102 & 211 & 0.87 \\
\hline NELSON $^{4}$ & $73 \cdot 7$ & 7289 & 40 & 0.5 & 7289 & 57 & 0.8 \\
\hline $\begin{array}{l}\text { UK Lung Cancer } \\
\text { Screening Trial }\end{array}$ & $66 \cdot 7$ & 2028 & 34 & 1.7 & 2028 & 8 & 0.4 \\
\hline \multicolumn{8}{|c|}{$\begin{array}{l}\text { *Proportion of detected cancers that were stage I. Results are from the first year of screening, except for NELSON, } \\
\text { in which round } 2 \text { and } 3 \text { screening data are presented together, reflecting the study design. }\end{array}$} \\
\hline
\end{tabular}

services in the screening process reduces the overall health-care cost by about a third. ${ }^{14}$ However, a 2015 survey ${ }^{15}$ of US screening centres suggested that only $36 \cdot 6 \%$ of these sites were prepared to provide optimal intensity tobacco cessation services

Under the provisions of the Affordable Care Act, public and private insurers in the USA are required to cover the cost of recommended cancer screening services without cost to the consumer. ${ }^{12}$ As evidence for screening increases and favourable cost data emerge, international interest in this new service is spreading, as reflected by reports outlining national lung cancer screening guidelines for China and Canada. ${ }^{16,17}$ Biomarker testing is also an area of intense ongoing interest. However, further research into improving screening efficiency is key to optimisation of its potentially great but fragile benefit. ${ }^{18}$ To reduce financial stress on health-care systems, screening should be delivered with integrated tobacco cessation.

\section{Treatment of early-stage lung cancer}

Surgery is the recommended treatment for patients with stage I-II non-small-cell lung cancer (NSCLC). ${ }^{19}$ 5-year survival is $77-92 \%$ for clinical stage IA, $68 \%$ for stage IB, $60 \%$ for stage IIA, and $53 \%$ for stage IIB. By pathological stage, 5-year survival is $80-90 \%$ for stage IA, $73 \%$ for stage IB, $65 \%$ for stage IIA, and $56 \%$ for stage IIB. ${ }^{20}$ Results of large meta-analyses ${ }^{21}$ have shown that video-assisted techniques give better quality of life and long-term outcomes compared with open lobectomy, and studies in stage I disease show equal or better survival after video-assisted techniques. The role of perioperative chemotherapy has been addressed in many randomised studies, ${ }^{22}$ and a meta-analysis ${ }^{23}$ found a survival benefit for patients with stage IB-IIIA disease, with a reduced hazard ratio (HR) of $0.83-0.92$ and absolute survival benefits of $5 \cdot 4-6.9 \%$ at 5 years. In a pooled analysis by the Lung Adjuvant Cisplatin Evaluation collaborative group, ${ }^{22}$ the 5 -year survival for the control group was $87.7 \%$ (including all-cause mortality). The role of targeted therapies in this setting is not defined..$^{24,25}$ Results of a large randomised trial (ECOG 1505) showed no benefit to using adjuvant bevacizumab in unselected early stage patients. ${ }^{26}$ Results from the large prospective placebocontrolled RADIANT study ${ }^{24}$ showed no benefit from the use of adjuvant epidermal growth factor receptor tyrosine kinase inhibitor (EGFR TKI) erlotinib; however, the study was not designed specifically for patients with tumours harbouring EGFR mutations..$^{24}$ Results of other studies have shown no effect of EGFR TKIs as adjuvant therapy in unselected patients. ${ }^{25}$ Ongoing large prospective studies (eg, the ALCHEMIST screening trial, NCT02194738) and other studies are investigating the role of EGFR TKIs in the EGFR-mutant population, ALK inhibitors in the ALK-positive population, and immunotherapy in the non-biomarker-selected population..$^{27,28}$

For patients with clinical stage I NSCLC who have medical contraindications to surgical resection or who refuse surgery, high-dose stereotactic body radiation therapy resulted in high local tumour control and low toxicity. Although there are no randomised data comparing stereotactic body radiation to other nonoperative first-line approaches such as radiofrequency ablation, standard radiotherapy, and chemotherapy, several phase 2 trials cite local tumour-control rates of more than $85 \%$ at 5 years. ${ }^{29,30}$ Stereotactic body radiation uses highly sophisticated planning and delivery technology, and the most common regimen delivers three fractions of $18 \cdot 0 \mathrm{~Gy}$, each to the target volume.

For patients with locally advanced NSCLC (stages IIIA-B) not amenable to surgical resection, and with good performance status, the current standard of care involves a 6-week course of thoracic radiotherapy with the concurrent delivery of doublet chemotherapy using either cisplatin or carboplatin and a second drug per week or every 3 weeks. ${ }^{31,32}$ The recommended total radiotherapy dose is 60-66 Gy, and best practice includes CT-based planning and the use of either threedimensional planning and delivery or intensity modulated radiation therapy. ${ }^{33}$ No targeted agent has yet been established as effective in conjunction with this chemotherapy and radiotherapy regimen. Multicentre trials have reported median survival times in excess of 2 years, and 5-year survival of $15-20 \% .{ }^{33,34}$

\section{Treatment of advanced lung cancer}

Therapeutic progress for subgroups of NSCLC can largely be attributed to the accumulation of molecular knowledge through emerging technology platforms (eg, next-generation sequencing and other omics platforms) and the development of new drugs that specifically target molecular abnormalities (appendix). Patients who have neoplasms with specific genomic aberrations have benefited from molecular targeted therapies (table 2). Up to $69 \%$ of patients with advanced NSCLC could have a potentially actionable molecular target (figure, table 3 ). ${ }^{35}$ 


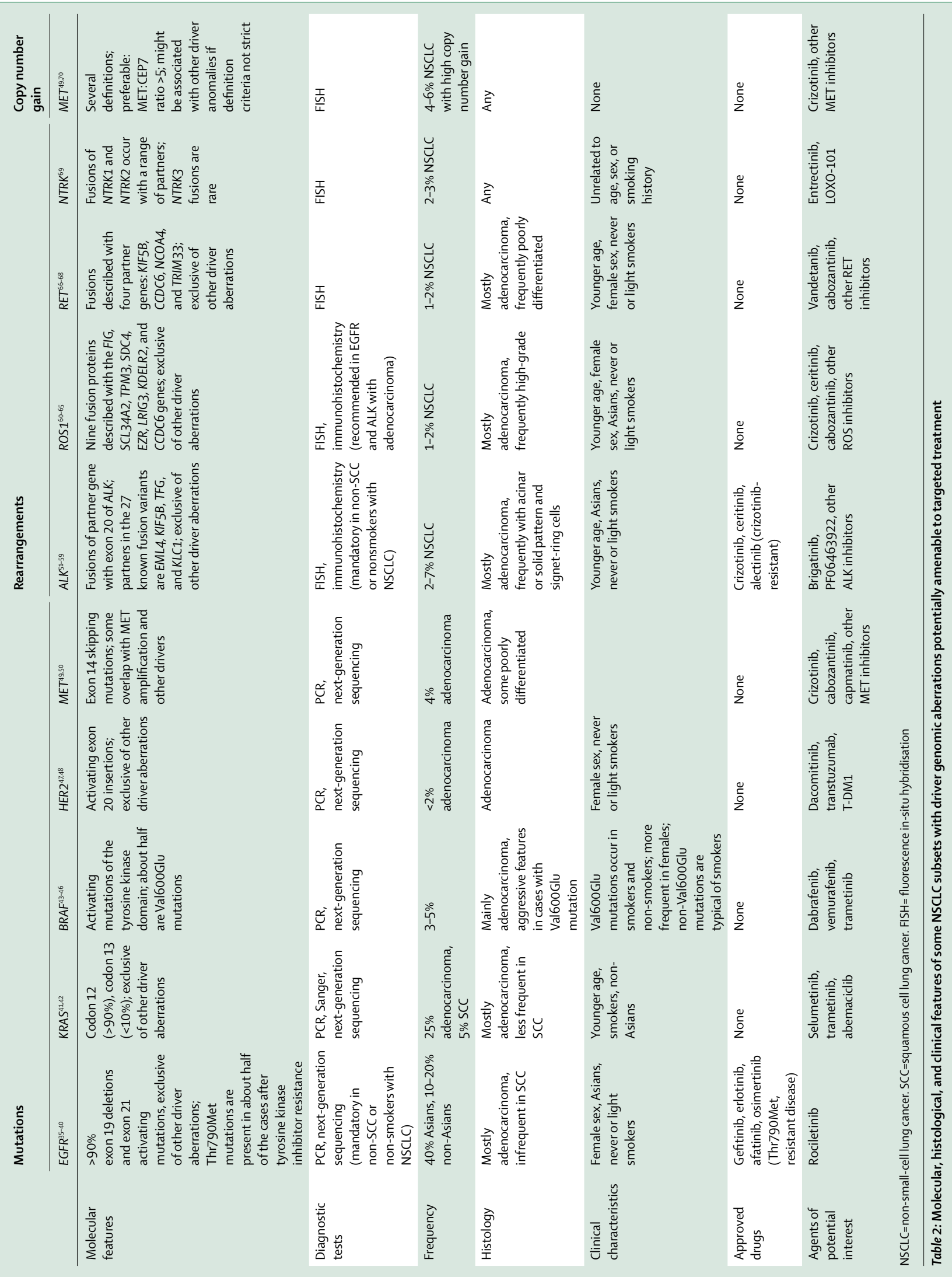




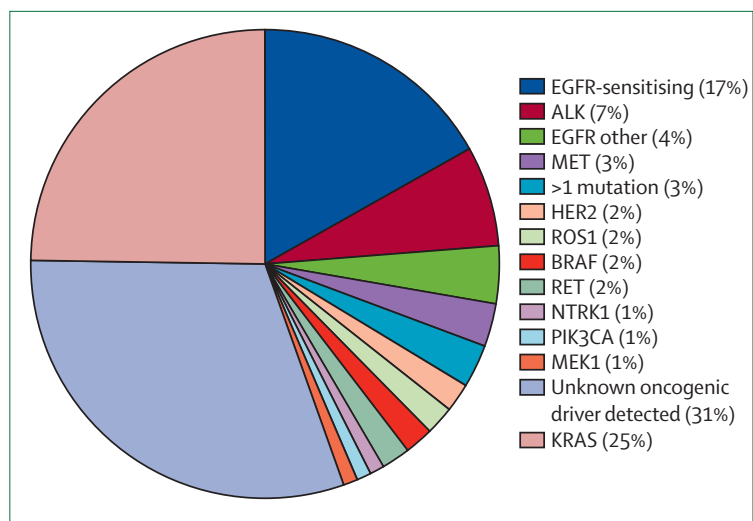

Figure: Frequency of molecular aberrations in driver oncogenes in lung adenocarcinomas

Molecular targeted therapies have advanced most for younger patients with adenocarcinoma, who are mostly never-smokers. For patients with advanced NSCLC who do not fit an approved molecular targeted therapy, the standard first-line treatment remains platinum-based doublet therapy with or without bevacizumab. Note that bevacizumab is not applicable to squamous cell histology.

An understanding of the immune landscape of tumours, including immune-evasion strategies, has led to breakthrough therapeutic advances and made a platform for future therapeutic developments.

\section{EGFR-activating mutations}

EGFR mutations occur in 10-20\% of patients not of east Asian descent with NSCLC and in about $40 \%$ of Asian patients, mostly in adenocarcinoma, younger women and girls, and never-smokers. ${ }^{35,71}$ EGFR TKI-sensitising mutations are most frequently seen in exon 19 (deletions) or in exon 21 (Leu858Arg). Nine large phase 3 randomised controlled trials (RCTs) ${ }^{36,37,72-74}$ established the superiority of EGFR TKIs as the first-line treatment in EGFRmutated NSCLC in terms of progression-free survival, objective response rate, and quality of life compared with chemotherapy. The impact of EGFR TKIs on survival has not been properly assessed in these trials of small sample size and high rate of cross-over, although a pooled analysis of the LUX-Lung 3 and LUX-Lung 6 trials did show an improvement in overall survival with EGFR TKIs compared with chemotherapy. ${ }^{75}$ The LUX-Lung studies also provide prospective data on afatinib use in uncommon mutations and some differences in outcome between EGFR mutations. ${ }^{75}$

Although second-generation TKIs (eg, afatinib) show an encouraging improvement in overall survival, they also have more toxic effects than first-generation TKIs. Therefore, which one is preferable as front-line treatment remains a question. Results from the LUX-Lung 7 study, ${ }^{38}$ a randomised phase $2 \mathrm{~b}$ study of 319 patients comparing afatinib with gefitinib as first-line therapy, showed a statistically significant prolongation of progression-free survival (median 11.0 months [95\% CI 10.6-12.9] vs $10 \cdot 9$ months $[9 \cdot 1-11 \cdot 5])$, with HR of $0.73(\mathrm{p}=0 \cdot 0165)$ in favour of afatinib, and an objective response rate of $70 \%$ with afatinib versus $56 \%$ with gefitinib $(p=0.008)$. The main adverse effects of afatinib were diarrhoea $(12.5 \%)$ and rash or acne $(9.4 \%)$. Drug-related interstitial lung disease was not seen in any patients treated with afatinib, but was reported in four patients treated with gefitinib. ${ }^{38}$

After EGFR TKI treatment, nearly all patients eventually had disease progression due to acquired resistance (although resistant clones might have been present before treatment commenced). Identified resistant mechanisms can be categorised as: secondary mutations in EGFR, bypass or alternative activations, or histological transformations. ${ }^{36,76, \pi}$

The gatekeeper Thr790Met mutation is the most frequent secondary EGFR mutation, occurring in 50-65\% of resistant re-biopsies. A third-generation irreversible inhibitor (AZD9291, osimertinib) that targets both Thr790Met and EGFR TKI-sensitising mutations showed an objective response rate of $61 \%$ and a median progression-free survival of 9.6 months in patients with Thr790Met-positive NSCLC who progressed after previous TKI therapy. ${ }^{39}$ The US Food and Drug Administration (FDA) and European Medicines Agency (EMA) approved osimertinib as a treatment for this population. Phase 1-2 studies of CO-1686 (rociletinib), HM61713, and others also reported impressive activity. ${ }^{40,78}$ For patients whose tumours do not have Thr790Met at time of progression after first-line EGFR TKI, platinumbased chemotherapy seems to be a rational option for those not participating in clinical trials.

Treatments after progressive disease develops while taking a first-line EGFR TKI should be selected according to the patient's failure pattern. ${ }^{79}$ For local progression, continuation of previous EGFR TKI therapy plus local intervention is recommended..$^{80}$ For slow progression, continuation of a first-line TKI with regular monitoring will hopefully result in the best outcome. ${ }^{81}$ For rapid systemic progression, switching to a second-line treatment based on the genetic profile of acquired resistance is currently being explored, but switching to doublet chemotherapy is still the standard of care. In this setting, continued administration of gefitinib combined with doublet chemotherapy is not recommended, based on results from the IMPRESS trial. ${ }^{82}$

Studies with the Thr790Met EGFR inhibitors identified novel mechanisms of acquired resistance to these third-generation TKIs, including the gatekeeper EGFR Cys797Ser mutation, HER2 and MET amplification, and MAPK activation. . $^{83,84}$

Because of the potential importance of genomic guided treatment at the time of progression and the frequent difficulty of obtaining sufficient tissue at the time of progression, much effort is going into the development of blood-based mutation assays. Encouraging results showed the detection of Thr790Met mutations in plasma with high specificity $(90-100 \%)$ and sensitivity $(85-90 \%){ }^{85-87}$ 
Combinations of EGFR TKIs with bevacizumab, chemotherapy, and checkpoint inhibition have been explored in clinical trials ${ }^{88-90}$ and might pave a way forward in the Thr790Met-negative resistant subgroup.

Brain metastases are an emerging challenge associated with poor prognosis. New agents such as AZD3759 and epitinib (HMPL-813) that target EGFR mutations have been designed for excellent penetration of the central nervous system. ${ }^{91}$

The discovery in 2007 of oncogenic $A L K$ gene rearrangements in $\mathrm{NSCLC}^{92,93}$ led to the understanding of its implications in the biology and natural history of the disease, and subsequently, the development of targeted drugs that have dramatically impacted the outcome of patients..$^{51,94}$

$A L K$ rearrangements result from inversions or translocations on chromosome 2 that fuse variable regions of a partner gene with exon 20 of the ALK gene. The most common translocated partner gene in NSCLC $A L K$ rearrangement is EML4. Altogether, 27 variants of $A L K$ fusion have been described..$^{52}$

ALK-driven tumours represent $2-7 \%$ of NSCLCs, ${ }^{51,53}$ and the median age at diagnosis is around 50 years, mostly in never-smokers or light smokers with adenocarcinomas. Patients are more frequently Asian, and $50-60 \%$ are men. ${ }^{51}$

The reference diagnostic assay for detecting $A L K$ fusions has been the Vysis LSI ALK Dual Color Break Apart FISH Probe (Abbott Molecular, IL, USA). ${ }^{94}$ Immunohistochemistry is also approved as a diagnostic assay. Of note, $A L K$ fusions are mutually exclusive with other oncogenic drivers, such as EGFR, ROS1, and $K R A S$, apart from in exceptional cases. ${ }^{53}$

Several ALK TKIs, including crizotinib, ceritinib, and alectinib, were developed and now constitute the backbone of treatment for patients with advanced ALK-positive NSCLC. ${ }^{53}$ Crizotinib targets ALK, ROS1, and MET. Patients who received crizotinib had rapid and durable responses with a favourable toxic profile in an expanded phase 1 trial and a subsequent phase 2 trial of patients mostly previously exposed to chemotherapy. ${ }^{94-96}$ Observed progression-free survival was 9.7 in the phase 1 trial and $8 \cdot 1$ months in the phase 2 trial. Based on these results, the FDA and countries including Japan granted approval to crizotinib in 2011. Two randomised trials have subsequently been completed that were the basis for regulatory approval by the EMA and other agencies. In the first trial (PROFILE 1007, n=347), crizotinib showed longer progression-free survival ( 7.7 vs 3.0 months) and higher objective response rate $(65 \%$ vs $20 \%)$ than pemetrexed or docetaxel in patients with advanced ALK-positive NSCLC progressing after first-line platinum-based chemotherapy. ${ }^{54}$ The second study (PROFILE 1014, $n=343$ ) showed the consistent superiority of crizotinib in terms of progression-free survival $(10.9 \mathrm{vs}$ 7.0 months) and objective response rate (74\% vs $45 \%)$ over pemetrexed plus platinum chemotherapy in

\begin{tabular}{|c|c|}
\hline & Status \\
\hline \multicolumn{2}{|l|}{ EGFR } \\
\hline Gefitinib & Approved \\
\hline Erlotinib & Approved \\
\hline Afatinib & Approved \\
\hline Osimertinib & Approved \\
\hline Necitumumab & Approved \\
\hline \multicolumn{2}{|l|}{ ALK } \\
\hline Crizotinib & Approved \\
\hline Alectinib & Approved \\
\hline Ceritinib & Approved \\
\hline Lorlatinib & Phase 2 \\
\hline Brigatinib & Phase 2 \\
\hline \multicolumn{2}{|l|}{ MET } \\
\hline Crizotinib & Phase 2 \\
\hline Cabozantinib & Phase 2 \\
\hline \multicolumn{2}{|l|}{ HER2 } \\
\hline Trastuzumab emtansine & Phase 2 \\
\hline Afatinib & Phase 2 \\
\hline Dacomitinib & Phase 2 \\
\hline \multicolumn{2}{|l|}{ ROS1 } \\
\hline Crizotinib & Approved \\
\hline Cabozantinib & Phase 2 \\
\hline Certinib & Phase 2 \\
\hline Lorlatinib & Phase 2 \\
\hline DS-6051b & Phase 1 \\
\hline \multicolumn{2}{|l|}{ BRAF } \\
\hline Vemurafenib & Phase 2 \\
\hline Dabrafenib & Phase 2 \\
\hline \multicolumn{2}{|l|}{ RET } \\
\hline Cabozantinib & Phase 2 \\
\hline Alectinib & Phase 2 \\
\hline Apatinib & Phase 2 \\
\hline Vandetanib & Phase 2 \\
\hline Ponatinib & Phase 2 \\
\hline Lenvatinib & Phase 2 \\
\hline \multicolumn{2}{|l|}{ NTRK1 } \\
\hline Entrectinib & Phase 2 \\
\hline LOXO-101 & Phase 2 \\
\hline Cabozantinib & Phase 2 \\
\hline DS-6501b & Phase 1 \\
\hline \multicolumn{2}{|l|}{ MEK1 } \\
\hline Trametinib & Phase 2 \\
\hline Selumetinib & Phase 3 \\
\hline Cobimetinib & Phase 1 \\
\hline \multicolumn{2}{|l|}{ PIK3CA } \\
\hline LY3023414 & Phase 2 \\
\hline PQR 309 & Phase 1 \\
\hline
\end{tabular}

Table 3: Developmental phases of available drugs against oncogenic proteins

untreated patients.5 ${ }^{55}$ Neither of these trials showed differences in overall survival among treatment groups, likely due to crossover of patients assigned to the chemotherapy regimen. 
In patients treated with crizotinib, relapse occurs within 1-2 years. CNS is the most frequent, and often only, site of relapse or progression regardless of the presence of CNS involvement at baseline. This might be due to the poor penetrance of crizotinib to the CNS (pharmacokinetic resistance), which is the consequence of drug efflux mediated by the ABCB1 pump. ${ }^{97}$ Various mechanisms of biological acquired resistance to crizotinib have been identified. . $2,98^{2}$

Treatment strategies resemble those for EGFR-mutant tumours. Novel second-generation ALK TKIs, including ceritinib and alectinib, among others, with higher inhibitory potency to the wild-type fused ALK protein, better affinity for the secondarily mutated proteins, and improved penetrance to the CNS, represent valuable treatment alternatives to chemotherapy when crizotinib fails. ${ }^{52,99}$ Approval was granted to ceritinib by FDA, EMA, and many other agencies for the treatment of ALK-positive NSCLC after failure on crizotinib (ie, disease progression), and alectinib was approved by FDA for patients who progress on crizotinib. Both drugs have shown durable response in a high proportion of patients, and ceritinib showed an objective response rate of $39-56 \%$ and a median progression-free survival of 5.7-6.9 months. $^{56,100}$ Phase 3 trials are comparing ceritinib with chemotherapy in platinum-exposed and chemotherapy-naive patients. Alectinib yielded responses in $45-56 \%$ of patients after failure of crizotinib treatment, with progression-free survival of 8.1-8.9 months in phase 1-2 trials. ${ }^{57,101}$ Alectinib is now being compared against chemotherapy in patients with crizotinib failure. Importantly, ceritinib and alectinib have shown response in patients with identifiable crizotinib-resistant tumour mutations at baseline.

Both alectinib and ceritinib have shown impressive activity in crizotinib-naive patients in single-arm studies (objective response rate $93 \%$ for alectinib and $67 \%$ for ceritinib) with progression-free survival of 19 months for alectinib and 27 months for ceritinib. ${ }^{102,103}$ Alectinib is being compared with crizotinib in treatment-naive patients in the ALEX phase 3 trial (NCT02075840), and one study (J-ALEX) $)^{104}$ reported increased efficacy of alectinib compared with crizotinib. A number of resistance mechanisms for second-generation ALK inhibitors, including new secondary mutations and alternative signalling routes, result in differential sensitivity patterns to existing ALK TKIs. Continuous assessment of changes in the disease genotype (eg, re-biopsy) will be helpful for more precise treatment guidance. ${ }^{52}$

Other ALK inhibitors in development include brigatinib, X-396, and PF-06463922..$^{52,58,59}$

\section{Other actionable aberrations in NSCLC}

Chromosomal rearrangement involving the ROS1 gene on 6q22 is observed in 1-2\% of NSCLC, mostly in adenocarcinomas. ${ }^{60,93}$ Nine fusion protein variants have been identified in NSCLC..$^{60,93}$ A fluorescence in-situ hybridisation (FISH) assay is currently deemed the gold standard for ROS1 fusion detection and is used in clinical studies. ${ }^{61}$ Reports support the use of immunohistochemistry assays for screening. ${ }^{62}$ Patients with ROS1-positive NSCLC are younger at diagnosis (median about 50 years of age), predominantly female, and never or light smokers. ${ }^{60}$

Crizotinib was assessed as an ROS1 inhibitor in a dedicated ROS1-positive NSCLC expansion cohort, and was approved by FDA for patients with ROS1-positive NSCLC. ${ }^{61}$ Of 50 patients, mostly pretreated with chemotherapy, $72 \%$ responded to crizotinib, with a median progression-free survival of 19.2 months. A European retrospective study of 30 patients reported similar results. ${ }^{63}$ Acquired resistance to crizotinib is mediated by secondary mutations of the kinase domain (CD74-ROS1 G2032R) $)^{64}$ or by bypass-tract activation, such as $c$-KIT or KRAS. ${ }^{65}$ Several other ROS1 inhibitors are currently being assessed, including ceritinib, cabozantinib, entrectinib, and PF06463922.

RET fusion products are detected in $1-2 \%$ of NSCLC, with greater frequency in never or light smokers bearing adenocarcinomas or adenosquamous tumours. ${ }^{105,106}$ Multi-targeted TKIs have shown activity against RET kinase in preclinical models, such as sunitinib, sorafenib, vandetanib, cabozantinib, alectinib, apatinib, lenvatinib, and ponatinib, and are now in phase 1 or 2 studies. ${ }^{66}$

Aberrant overexpression, amplification, and activating mutations of the MET receptor tyrosine kinase have been observed in specific subsets of lung tumours. ${ }^{49}$ Two randomised trials ${ }^{107,108}$ reported that outcomes for pretreated patients not selected for MET genomic abnormalities, who received a MET inhibitor (tivantinib or onartuzumab) in combination with erlotinib, were the same as those treated with the EGFR TKI alone. MET gene amplification occurs in about $4 \%$ of lung adenocarcinomas and 1\% of squamous cell lung cancers (SCC). ${ }^{49}$ Evidence suggests that patients with high amplification (ie, MET:CEP7 ratio >5) might have a high response rate $(>35 \%)$ to $\mathrm{MET}$ inhibitors such as crizotinib. $^{70}$

Paik and colleagues ${ }^{50}$ reported oncogenic mutations in $M E T$ exon 14 splice sites that cause exon 14 skipping and lead to increased kinase catalytic activity. This mutation is seen in 3-4\% of lung adenocarcinomas, typically in the absence of other drivers. Paik and colleagues previously reported response to the MET inhibitors crizotinib and cabozantinib in five patients with lung adenocarcinomas bearing the MET exon mutation.

HER 2 overexpression occurs in $35 \%$ of lung cancers, and amplification occurs in $10 \%$ of lung cancers. The data so far do not support routine clinical use of HER2-directed therapies in this population beyond clinical trials. HER2 mutations are found in about $2 \%$ of NSCLC, mainly in women, never-smokers, and adenocarcinoma histology. ${ }^{47} \mathrm{~A}$ phase 2 trial $^{48}$ of dacomitinib (objective response rate 12\%) supports the 
efficacy of anti-HER2 agents alone or in combination with chemotherapy.

$B R A F$ mutations are detected in 3-5\% of lung cancers, mainly in smokers bearing adenocarcinomas. ${ }^{43,44}$ The Val600Glu mutation is reported in half of patients with $B R A F$-mutated lung adenocarcinomas. A study included 20 pre-treated patients with BRAF-mutated NSCLC, 18 of whom had the Val600Glu mutation. ${ }^{45}$ The objective response rate was $42 \%$ and median progression-free survival was $7 \cdot 2$ months. A phase 2 study in the same patient population using dabrafenib gave consistent results. ${ }^{46} \mathrm{~A}$ higher activity (objective response rate $63 \%$ ) was documented with dabrafenib combined with the MEK1 inhibitor trametinib, as previously seen in melanoma. ${ }^{109}$

KRAS mutations are common aberrations in lung cancer and are frequently found in adenocarcinomas $(25 \%)$, particularly in smokers of non-Asian ethnicity. ${ }^{110}$ Development of therapeutics to target this phenotype has been remarkably frustrating. MEK inhibitors (trametinib and selumetinib) have shown signs of activity, more in combination with chemotherapy than as monotherapy. ${ }^{41,42}$

NTRK1 and NTRK2 rearrangements are detected in $1-2 \%$ of NSCLC and several NTRK inhibitors are under investigation. ${ }^{69}$

The Cancer Genome Atlas reported that $96 \%$ of 178 lung SCCs harboured genomic abnormalities, including mutations or amplification of FGFR, the PI3K pathway, DDR2, EGFR and HER2, and the tumour suppressor genes TP53 and P16. ${ }^{111}$ FGFR amplification was seen in about $5-22 \%$ of SCC, and DDR2 mutations were seen in about $4 \%$ of SCC. ${ }^{112,113}$ None of these alterations defines a subset of SCC whose patients are known to benefit from specific therapies, although a number of agents targeting these dysregulated pathways are being assessed preclinically and in early clinical trials.

In SCLC, there is an almost universal inactivation of TP53 and RB1, sometimes by complex genomic rearrangements. ${ }^{114}$ About a quarter of cases show inactivating mutations in the NOTCH gene family.

Unlike other types of lung cancer, SCLC has had no breakthrough agents in the last 25 years, with only one agent approved, topotecan (for second-line treatment). SCLC is usually chemo-sensitive but in most cases resistance rapidly develops. ${ }^{115}$ Thus, essentially all patients of any stage receive a doublet combination of etoposide (or irinotecan in Japan) with cisplatin or carboplatin.

Limited stage disease (ie, tumours that are located in the ipsilateral hemithorax and treatable with a single radiation field) occurs in only one-third of patients with SCLC and is potentially curable. Combined-modality therapy (chemotherapy and radiotherapy) has long been the mainstay of therapy for this condition, but more recent data suggest a role for surgery in early stage disease. Prophylactic cranial irradiation seems to improve outcomes in patients who have responded to initial therapy. ${ }^{116}$
Anti-VEGF inhibitors have been used in combination with chemotherapy for the treatment of lung cancer on the basis of modestly improved outcomes. For safety reasons, these agents have been restricted to patients with adenocarcinoma with a low risk of haemoptysis. A novel monoclonal antibody directed at the VEGF receptor, ramucirumab, has been approved by the FDA and EMA for use in combination with docetaxel in the second-line treatment of squamous and non-squamous NSCLC. ${ }^{117}$ Another antiangiogenic agent, ${ }^{118}$ the multikinase inhibitor nintedanib, resulted in similar survival benefits when combined with docetaxel, but only in patients with adenocarcinoma. Nintedanib is EMA approved but not FDA approved.

Necitumumab is another monoclonal antibody against EGFR, which was shown to improve survival in untreated patients with advanced SCC when combined with cisplatin and gemcitabine (HR 0.84, 95\% CI 0.74-0.96; $\mathrm{p}=0 \cdot 01) .{ }^{118}$ The drug was approved by the FDA but restricted to those tumours with positive EGFR expression by the EMA. ${ }^{119}$

\section{Immunotherapy}

Lung cancer initiation and progression depends not only on the evolving genomics and molecular properties of cancer cells but also on their interaction with the tumour environment, specifically with the immune system. ${ }^{120}$ Therapeutic approaches that modulate the immune system in patients with lung cancer have traditionally focused on vaccines, and have generally been ineffective, probably due to insufficient or inadequate immune activation (TG4010, which has shown some positive results, remains under investigation). ${ }^{120-122}$ Immunotherapy approaches have focused on a series of ligands and receptors that inhibit or stimulate the immunological synapse. $^{123}$

Inhibitory checkpoint molecules generated upon T-cell activation, such as those that regulate the immunological synapse between $\mathrm{T}$ cells and dendritic cells in lymph nodes (CTLA-4-B7.1), thereby suppressing T-cell activation, or between $\mathrm{T}$ cells and tumour cells in the tumour bed (programmed death-1 [PD-1]-programmed death-ligand [PD-L]1, PD-L2), hampering immune rejection or the effector phase, are currently the most relevant targets for immunotherapy. Antibody-directed therapies against these checkpoints have shown remarkable early success in many malignancies and already have a major role in the management of advanced lung cancer and other tumours (table 4). ${ }^{124}$

Several monoclonal antibodies directed to the PD-1 receptor (nivolumab, pembrolizumab) or its ligand PD-L1 (atezolizumab, durvalumab, avelumab) have reached the clinic, and others are in preclinical development. Early clinical trials with these agents have shown rapid and durable responses in about $14-20 \%$ of pre-treated patients with advanced NSCLC. ${ }^{128-134}$ Importantly, even though progression-free survival figures are not impressive 


\begin{tabular}{|c|c|c|c|c|c|c|c|c|c|c|c|}
\hline & \multicolumn{2}{|c|}{$\begin{array}{l}\text { CheckMate } 017 \\
\text { phase } 3^{125}\end{array}$} & \multicolumn{2}{|c|}{$\begin{array}{l}\text { CheckMate } 057 \\
\text { phase } 3^{126}\end{array}$} & \multicolumn{3}{|c|}{ KEYNOTE-010 phase $3^{127}$} & \multicolumn{2}{|c|}{ POPLAR phase $2^{128}$} & \multirow{2}{*}{$\begin{array}{l}\begin{array}{l}\text { Durvalumab } \\
\text { phase } \mathbf{1 b}^{\mathbf{1 2 9}}\end{array} \\
\text { Durvalumab }\end{array}$} & \multirow{2}{*}{$\begin{array}{l}\begin{array}{l}\text { Avelumab } \\
\text { phase } \mathbf{1 b}^{13}\end{array} \\
\text { Avelumab }\end{array}$} \\
\hline & Nivolumab & Docetaxel & Nivolumab & Docetaxel & $\begin{array}{l}\text { Pembrolizumab } \\
2 \mathrm{mg} / \mathrm{kg}\end{array}$ & $\begin{array}{l}\text { Pembrolizumab } \\
10 \mathrm{mg} / \mathrm{kg}\end{array}$ & Docetaxel & Atezolizumab & Docetaxel & & \\
\hline Patients (n) & 135 & 137 & 292 & 290 & 345 & 346 & 343 & 144 & 143 & 198 & 184 \\
\hline \multicolumn{12}{|l|}{ Response rate (\%) } \\
\hline All patients & 20 & 9 & 19 & 12 & 18 & 19 & 9 & 15 & 15 & 16 & 14 \\
\hline PD-L1 positive & 21 & 8 & 36 & 13 & 30 & 29 & 8 & 38 & 13 & 27 & 16 \\
\hline PD-L1 negative & 15 & 12 & 10 & 14 & NA & NA & NA & 8 & 10 & 5 & 10 \\
\hline \multicolumn{12}{|c|}{ Median progression-free survival (months) } \\
\hline All patients & $3 \cdot 5$ & $2 \cdot 8$ & $2 \cdot 3$ & $4 \cdot 2$ & 3.9 & $4 \cdot 0$ & $4 \cdot 0$ & $2 \cdot 7$ & $3 \cdot 0$ & NA & $2 \cdot 9$ \\
\hline PD-L1 positive & $4 \cdot 8$ & $3 \cdot 1$ & $5 \cdot 0$ & $3 \cdot 8$ & $5 \cdot 0$ & $5 \cdot 2$ & $4 \cdot 1$ & $2 \cdot 8$ & $3 \cdot 0$ & NA & $3 \cdot 0$ \\
\hline PD-L1 negative & $4 \cdot 2$ & $2 \cdot 9$ & $2 \cdot 1$ & $4 \cdot 2$ & NA & NA & NA & $1 \cdot 7$ & $4 \cdot 1$ & NA & 1.4 \\
\hline \multicolumn{12}{|c|}{ Median overall survival (months) } \\
\hline All patients & $9 \cdot 2$ & $6 \cdot 0$ & $12 \cdot 2$ & 9.4 & $10 \cdot 4$ & $12 \cdot 7$ & $8 \cdot 5$ & $12 \cdot 6$ & $9 \cdot 7$ & NA & 8.9 \\
\hline PD-L1 positive & 10 & $6 \cdot 4$ & $19 \cdot 4$ & $8 \cdot 1$ & $14 \cdot 9$ & $17 \cdot 3$ & $8 \cdot 2$ & $15 \cdot 5$ & $9 \cdot 2$ & NA & $8 \cdot 4$ \\
\hline PD-L1 negative & $8 \cdot 5$ & $6 \cdot 1$ & $9 \cdot 8$ & $10 \cdot 1$ & NA & NA & NA & $9 \cdot 7$ & $9 \cdot 7$ & NA & $4 \cdot 6$ \\
\hline Histology & $\mathrm{SCC}$ & $\mathrm{SCC}$ & Non-SCC & Non-SCC & All comers & All comers & All comers & All comers & All comers & All comers & All comers \\
\hline Setting & Second line & $\begin{array}{l}\text { Second } \\
\text { line }\end{array}$ & Second line & $\begin{array}{l}\text { Second } \\
\text { line }\end{array}$ & Second line & Second line & Second line & Second line & Second line & Pre-treated & Pre-treated \\
\hline \multicolumn{12}{|l|}{ PD-L1 expression } \\
\hline Positive & $\geqq 5 \%$ & $\geqq 5 \%$ & $\geqq 5 \%$ & $\geqq 5 \%$ & $\begin{array}{l}\text { Highly positive } \\
\geqq 50 \% \text {; positive } \\
\geqq 1 \%\end{array}$ & $\begin{array}{l}\text { Highly positive } \\
\geqq 50 \% \text {; positive } \\
\geqq 1 \%\end{array}$ & $\begin{array}{l}\text { Highly } \\
\text { positive } \\
\geqq 50 \% \text {; } \\
\text { positive } \\
\geqq 1 \%\end{array}$ & \multicolumn{2}{|c|}{$\begin{array}{l}\text { Tumour cell } 1-3 \text { or tumour- } \\
\text { infiltrating immune cells 1-3 }\end{array}$} & $\geqq 25 \%$ & $\geqq 1 \%$ \\
\hline Negative & $<5 \%$ & $<5 \%$ & $<5 \%$ & $<5 \%$ & $\begin{array}{l}<1 \% \text { (not } \\
\text { included) }\end{array}$ & $\begin{array}{l}<1 \% \text { (not } \\
\text { included) }\end{array}$ & $\begin{array}{l}<1 \% \text { (not } \\
\text { included) }\end{array}$ & \multicolumn{2}{|c|}{$\begin{array}{l}\text { Tumour cell } 0 \text { and tumour- } \\
\text { infiltrating immune cells } 0\end{array}$} & $<25 \%$ & $<1 \%$ \\
\hline
\end{tabular}

Percentages rounded. PD-1=programmed death-1. PD-L1=programmed death ligand-1. SCC=squamous cell cancer. NA=not available.

Table 4: Trials of anti-PD-1/PD-L1 inhibitors in patients with advanced NSCLC who were pre-treated with chemotherapy

(median 2-4 months; progression-free survival at 1 year $20 \%)$, survival outcomes are remarkable. In the $27-$ month follow-up of a cohort of 129 patients with NSCLC treated with nivolumab, ${ }^{131} 2$-year survival was $24 \%$ in the overall population and $42 \%$ in the subset of patients treated at the dose selected for further development $(3 \mathrm{mg} / \mathrm{kg}$ every 2 weeks); 3 -year survival was $18 \%$ in the overall population and $27 \%$ in the development dose subset of patients. Clinical efficacy appeared independent of histology, but in most of the trials greater benefit was observed in smokers and in patients with PD-L1-positive expression. The toxic profile of these agents is quite favourable, with about $10 \%$ of patients developing severe (grades III-IV) adverse events. ${ }^{125-130,132-134}$ The most frequent adverse effects observed were asthenia, fatigue, loss of appetite, nausea, and diarrhoea. Less than $10 \%$ of patients developed immune-related side-effects including rash, colitis, transaminitis, pneumonitis, and endocrinopathies.

Clinical efficacy and safety of the anti-PD-1 or anti-PD-L1 agents is supported by four randomised studies. ${ }^{125-128}$ Two trials compared nivolumab to docetaxel in patients who progressed to platinum-based chemotherapy, in SCC (CheckMate 017 trial) ${ }^{125}$ and non-SCC NSCLC (CheckMate 057 trial). ${ }^{126}$ In patients with SCC, nivolumab resulted in improved survival (median 9.2 vs 6.0 months,
HR 0.59; $<<0 \cdot 001)$, progression-free survival $(3 \cdot 5$ vs $2 \cdot 8$, $0.62 ; \mathrm{p}<0.001)$, and response rate $(20 \%$ vs $9 \%, \mathrm{p}<0 \cdot 008)$ over docetaxel. ${ }^{130}$ Nivolumab benefits were largely independent of clinical and tumour characteristics, including PD-L1 expression. In the non-SCC trial, nivolumab improved survival (median $12.2 \mathrm{vs} 9.4$ months, HR 0.73$)$ and response rate $(\mathrm{p}<0.02)$ but not progressionfree survival in the overall population. ${ }^{126}$ Treatment effect was seen in all patient subgroups except for never-smokers and those with wild-type EGFR tumours. In non-SCC, PD-L1 expression emerged as a substantial determinant of nivolumab benefit. Nivolumab has obtained regulatory approval in the USA (SCC and non-SCC) and the EU (SCC) for the treatment of advanced disease in patients who have progressed on first-line chemotherapy.

Irrespective of the use of a different clone and assay for PD-L1 determination, along with different criteria for positivity (ie, staining of immune cells within the tumour was taken into account), the benefit from the checkpoint inhibitor was mostly restricted to the PD-L1-positive tumour population. A randomised phase 3 trial of pembrolizumab versus docetaxel in patients harbouring PD-L1-positive tumours ( $>1 \%$ of cells) favoured the anti-PD-1 treatment, and the magnitude of the survival benefit was related to PD-L1 expression (HR of 0.53 if 
PD-L1 >50\%; HR of 0.76 if PD-L1 expression 1-49\%). ${ }^{127}$ Pembrolizumab has been FDA approved for second or further lines of treatment if tumour expression of PD-L1 is encountered in $\geq 50 \%$ of cells, independent of histology. Although results from comparative studies of immune therapy and chemotherapy as first-line treatment for advanced NSCLC are still pending, Merck announced that a large study ${ }^{135}$ met its endpoints of progression-free survival and overall survival benefit for pembrolizumab versus chemotherapy in patients with PD-L1-expressing tumours $(\geq 50 \%)$.

Atezolizumab showed benefit over docetaxel in a randomised phase 2 trial including all NSCLC histologies. ${ }^{128}$

Overall data suggest PD-1 inhibitors are a preferred second-line treatment over standard chemotherapy in SCC and at least in PD-L1-positive, non-SCC of the lung. However, a remaining question is the optimal definition of PD-L1 expression in terms of prediction of benefit. Not all patients with PD-L1-positive NSCLC benefit from these agents, and some PD-L1-low-expressing or PD-L1-negative tumours do. All the PD-L1 assays differ in terms of antibodies used, assessment methods, targeting cells, and cutoffs for positive and negative results. ${ }^{136}$ To elucidate similarities and differences between the different PD-L1 assays, comparative studies are ongoing on a standardised set of NSCLC tumours. ${ }^{136}$

In previously untreated patients, results of early trials have reported encouraging results with anti-PD-1 or antiPD-L1 inhibitors, including 1-year survival exceeding 70\% in PD-L1-positive tumours. ${ }^{117,137}$ Several trials are currently comparing these agents with platinum combination regimens as front-line therapy. Trials are also ongoing in earlier disease settings (stage III, post-surgery), and early data are encouraging in other thoracic malignancies, such as small-cell lung cancer (SCLC) and mesothelioma. ${ }^{138,139}$

Maintenance therapy for patients with advanced NSCLC

The optimal duration of treatment for patients with advanced NSCLC has been investigated in several studies. The administration of 4-6 cycles of combination chemotherapy followed by observation has become the standard of care for the first-line treatment of advanced NSCLC. ${ }^{140,141}$

To date, both switch therapy strategies (in which a different therapy than the first-line therapy is used) with pemetrexed $^{142}$ and erlotinib, ${ }^{143}$ or continuation maintenance with pemetrexed ${ }^{144}$ improved outcomes, including overall survival and progression-free survival (table 5). Several meta-analyses have supported the impact of maintenance treatment approaches on efficacy outcomes and toxicity. ${ }^{150,151}$ Overall, these studies substantiated a highly significant impact from maintenance therapy on progression-free survival (HR 0.53-0.67) and, to a lesser extent, on overall survival $(0 \cdot 85-0 \cdot 88)$, with some increases in clinically relevant toxicities but maintaining the quality of life of treated

\begin{tabular}{|c|c|c|c|c|}
\hline & n & $\begin{array}{l}\text { Maintenance } \\
\text { drug }\end{array}$ & $\begin{array}{l}\text { Progression-free } \\
\text { survival HR } \\
(95 \% \mathrm{CI})\end{array}$ & $\begin{array}{l}\text { Overall survival HR } \\
(95 \% \mathrm{Cl})\end{array}$ \\
\hline \multicolumn{5}{|c|}{ Switch maintenance trials } \\
\hline Westeel et $\mathrm{al}^{145}$ & 181 & Vinorelbine & $0.77(0.56-1 \cdot 07)$ & $1.08(0.79-1.47)$ \\
\hline Fidias et $\mathrm{al}^{146}$ & 309 & Docetaxel & $0.71(0.55-0.92)$ & $0.84(0.65-1.08)$ \\
\hline Cappuzzo et a $\left.\right|^{143}$ & 889 & Erlotinib & $0.71(0.62-0.82)$ & $0.81(0.70-0.95)$ \\
\hline Ciuleanu et $\mathrm{a}^{142}$ & 663 & Pemetrexed & $0.60(0.49-0.73)$ & $0.79(0.65-0.95)$ \\
\hline \multicolumn{5}{|c|}{ Continuation maintenance trials } \\
\hline Paz-Ares et al ${ }^{144}$ & 539 & Pemetrexed & $0.62(0.49-0.79)$ & $0.78(0.64-0.96)$ \\
\hline Brodowicz et $\mathrm{al}^{147}$ & 206 & Gemcitabine & $0.69(0.56-0.86)$ & $0.84(0.52-1 \cdot 30)$ \\
\hline Belani et $\mathrm{al}^{148}$ & 255 & Gemcitabine & $1.09(0.81-1.45)$ & $0.97(0.72-1 \cdot 30)$ \\
\hline Perol et a $\left.\right|^{149}$ & 309 & Gemcitabine & $0.56(0.44-0.72)$ & $0.89(0.67-1.15)$ \\
\hline
\end{tabular}

patients. Switch maintenance strategies are not used frequently in practice compared with continuation maintenance, as physicians and patients most often prefer to extract the maximum benefit from a given therapy before switching to an alternative treatment.

Maintenance therapy with an EGFR inhibitor is indicated for patients with activating EGFR TKIsensitising tumour mutations who for any reason (eg, delayed information on EGFR mutation profiling) are given first-line chemotherapy. ${ }^{152}$

Several factors influence the decision to implement maintenance therapy. These included tumour histology (pemetrexed being indicated only in patients with nonsquamous NSCLC), genomics, response to induction, patient health status (performance status $\geq 2$ precludes benefit from this approach) and, most importantly, patient choice. ${ }^{141}$ From the patient's perspective, an overall survival benefit of at least several months (eg, 3 months in the Paramount trial) ${ }^{144}$ or better symptom control is expected, to balance mild-to-moderate sideeffects.

\section{Conclusion}

Although lung cancer has long been a disease characterised by late-stage diagnosis and no progress in treatment options, the last decade has yielded encouraging results with lung cancer screening in high-risk populations and substantial progress with systemic therapies for molecular subgroups of patients with advanced disease. Further progress is expected for these patient subgroups through the development of next-generation drugs that have more-specific target effects, and target of specific resistant mutations, creating a chronic therapeutic pathway.

Furthermore, new molecular targets are continuously detected, prompting the development of new therapies. For many subgroups of patients with NSCLC, future combination therapy (using targeted therapies or immunotherapies) could be the ultimate curative option. 


\section{Contributors}

Each author wrote a section of the manuscript. FRH coordinated the integration and editing of the manuscript and provided the figure. JLM, GVS, and LP-A provided the tables. All authors revised and edited the manuscript.

\section{Declaration of interests}

FRH has received compensation for participating in scientific advisory boards for Bristol-Myers Squibb, Genentech-Roche, AstraZeneca, Merck, Lilly Oncology, Celgene, Clovis, Boehringer Ingelheim, and Pfizer, outside the submitted work. GVS reports personal fees from Eli Lilly, Roche, Pfizer, AstraZeneca, and Clovis Oncology, outside the submitted work. Y-LW reports personal fees from Roche, AstraZeneca, Eli Lilly, Pfizer, and Sanofi, outside the submitted work. LP-A reports personal fees from BMS, MSD, Roche, Lilly, AstraZeneca, Clovis, Novartis, and Boehringer Ingelheim, outside the submitted work. JLM, RK, and WJC declare no competing interests.

\section{References}

1 Ferlay J, Soerjomataram I, Dikshit R, et al. Cancer incidence and mortality worldwide: sources, methods and major patterns in GLOBOCAN 2012. Int J Cancer 2015; 136: E359-86.

2 American Cancer Society. Cancer facts \& figures 2015. Atlanta: American Cancer Society, 2015. http://www.cancer.org/acs/groups/ content/@editorial/documents/document/acspc-044552.pdf (accessed Dec 31, 2015)

3 Aberle DR, Adams AM, Berg CD, et al. Reduced lung-cancer mortality with low-dose computed tomographic screening. N Engl J Med 2011; 365: 395-409.

4 Horeweg N, van Rosmalen J, Heuvelmans MA, et al. Lung cancer probability in patients with CT-detected pulmonary nodules: a pre-specified analysis of data from the NELSON trial of low-dose CT screening. Lancet Oncol 2014; 15: 1332-41.

5 Field JK, Duffy SW, Baldwin DR, et al. UK lung cancer RCT pilot screening trial: baseline findings from the screening arm provide evidence for the potential implementation of lung cancer screening. Thorax 2015; 71: 161-70.

6 Henschke C, Yip R, Yankelevitz DF, et al. Definition of a positive test result in computed tomography screening for lung cancer: a cohort study. Ann Intern Med 2013; 158: 246-52.

7 Kazerooni EA, Armstrong MR, Amorosa JK, et al. ACR CT accreditation program and the lung cancer screening program designation. J Am Coll Radiol 2015; 12: 38-42.

8 Pinsky PF, Gierada DS, Black W, et al. Performance of Lung-RADS in the National Lung Screening Trial: a retrospective assessment. Ann Intern Med 2015; 162: 485-591.

9 Frank L, Christodoulou E, Kazerooni EA. Radiation risk of lung cancer screening. Semin Respir Crit Care Med 2013; 34: 738-47.

10 Yoshizawa A, Motoi N, Riely GJ, et al. Impact of proposed IASLC/ ATS/ERS classification of lung adenocarcinoma: prognostic subgroups and implications for further revision of staging based on analysis of 514 stage I cases. Mod Pathol 2011; 24: 653-64.

11 Yankelevitz DF, Yip R, Smith JP, et al. CT screening for lung cancer: nonsolid nodules in baseline and annual repeat rounds. Radiology 2015; 277: 555-64.

12 Mulshine JL, D’Amico A. Issues with implementing a high-quality lung cancer screening program. CA Cancer J Clin 2014; 64: 352-63.

13 Flores R, Bauer T, Aye R, et al. Balancing curability and unnecessary surgery in the context of computed tomography screening for lung cancer. J Thorac Cardiovasc Surg 2014; 147: 1619-26.

14 Villanti AC, Jiang Y, Abrams DB, Pyenson BS. A cost-utility analysis of lung cancer screening and the additional benefits of incorporating smoking cessation interventions. PLoS One 2013; 8: e71379.

15 Ostroff JS, Copeland A, Borderud SP, Li Y, Shelley DR, Henschke CI. Readiness of lung cancer screening sites to deliver smoking cessation treatment: current practices, organizational priority, and perceived barriers. Nicotine Tob Res 2015; 18: 1067-75.

16 Zhou QH, Fan YG, Bu H, et al. China national lung cancer screening guideline with low-dose computed tomography (2015 version). Thorac Cancer 2015; 6: 812-18.

17 Canadian Task Force on Preventive Health Care. Recommendations on screening for lung cancer. CMAJ 2016; 188: 425-32.

18 Bailar JC. Screening for lung cancer-where are we now? Am Rev Respir Dis 1984; 130: 541-42.
19 Vansteenkiste J, Crinò L, Dooms C, et al. 2nd ESMO Consensus Conference on Lung Cancer: early-stage non-small-cell lung cancer consensus on diagnosis, treatment and follow-up. Ann Oncol 2014; 25: $1462-74$.

20 Goldstraw P, Chansky K, Crowley J, et al. The IASLC Lung Cancer Staging Project: proposals for revision of the TNM stage groupings in the forthcoming (eighth) edition of the TNM classification for lung cancer. J Thorac Oncol 2016; 11: 39-51.

21 Cao C, Manganas C, Ang SC, Peeceeyen S, Yan TD. Video-assisted thoracic surgery versus open thoracotomy for non-small cell lung cancer: a meta-analysis of propensity score-matched patients. Interact Cardiovasc Thorac Surg 2013; 16: 244-49.

22 Pignon JP, Tribodet H, Scagliotti GV, et al. Lung adjuvant cisplatin evaluation: a pooled analysis from the LACE Collaborative Group. J Clin Oncol 2008; 26: 3552-59.

23 NSCLC Meta-analysis Collaborative Group. Preoperative chemotherapy for non-small-cell lung cancer: a systematic review and meta-analysis of individual participant data. Lancet 2014; 383: 1561-71.

24 Kelly K, Altorki NK, Eberhardt WE, et al. Adjuvant erlotinib versus placebo in patients with stage IB-IIIA non-small cell lung cancer (RADIANT): a randomized, double-blind, phase III trial. J Clin Oncol 2015; 33: 4007-14.

25 Hirsch FR, Bunn PA Jr. Adjuvant TKIs in NSCLC: what can we learn from RADIANT? Nat Rev Clin Oncol 2015; 12: 689-90.

26 Wakelee HA, Dahlberg SE, Keller SM, et al. Randomized phase III trial of adjuvant chemotherapy with or without bevacizumab in resected non-small cell lung cancer (NSCLC): Results of E1505. World Conference on Lung Cancer; Denver, CO, USA; Sept 6-9, 2015. Abstract 1608

27 Goss GD, O'Callaghan C, Lorimer I, et al. Gefitinib versus placebo in completely resected non-small cell lung cancer; result of the NCIC-CTG BR 19 study. J Clin Oncol 2013; 31: 3320-26.

28 National Cancer Institute. ALCHEMIST (Adjuvant Lung Cancer Enhancement Marker Identification and Sequencing Trials) http//www.cancer.gov/types/lung/research/alchemist (accessed March 25, 2016).

29 Timmerman R, Paulus R, Galvin J, et al. Stereotactic body radiation therapy for inoperable early stage lung cancer. JAMA 2010; 303: 1070-76.

30 Fakiris AJ, McGarry RC, Yiannoutsos CT, et al. Stereotactic body radiation therapy for early-stage non-small-cell lung carcinoma: four-year results of a prospective phase II study. Int J Radiat Oncol Biol Phys 2009; 75: 677-82.

31 Curran WJ Jr, Paulus R, Langer CJ, et al. Sequential vs. concurrent chemoradiation for stage III non-small cell lung cancer: randomized phase III trial RTOG 9410. J Natl Cancer Inst 2011; 103: 1452-60.

32 Auperin A, Pechoux C, Rolland E, et al. Meta-analysis of concomitant versus sequential radiochemotherapy in locally advanced non-small-cell lung cancer. J Clin Oncol 2010; 28: 2181-90.

33 Bradley J, Paulus R, Komaki R, et al. A randomized phase III comparison of standard-dose ( $60 \mathrm{~Gy}$ ) versus high-dose ( $74 \mathrm{~Gy})$ conformal radiotherapy with concurrent and consolidation carboplatin/paclitaxel with or without cetuximab for patients with stage IIIA/IIIB non-small cell lung cancer: RTOG 0617. Lancet Oncol 2015; 16: 187-99.

34 Senan S, Brade A, Wang LH, et al. PROCLAIM: Randomized phase III trial of pemetrexed-cisplatin or etoposide-cisplatin plus thoracic radiation therapy followed by consolidation chemotherapy in locally advanced nonsquamous non-small-cell lung cancer. J Clin Oncol 2016; 34: 953-62.

35 Tsao AS, Scagliotti GV, Bunn PA Jr, et al. Scientific advances in lung cancer 2015. J Thorac Oncol 2016; 11: 613-38.

36 Tan DSW, Yom SS, Tsao MS, et al. The International Association for the Study of Lung Cancer consensus statement on optimizing management of EGFR mutation positive NSCLC: status in 2016. $J$ Thorac Oncol 2016; 11: 946-63.

37 Rosell R, Carcereny E, Gervais R, et al. Erlotinib versus standard chemotherapy as first-line treatment for European patients with advanced EGFR mutation-positive non-small-cell lung cancer (EURTAC): a multicentre, open-label, randomised phase 3 trial. Lancet Oncol 2012; 13: 239-46.

38 Park K, Tan E-H, O'Byrne K, et al. Afatinib versus gefitinib as first-line treatment of patients with EGFR mutation-positive non-small-cell lung cancer (LUX-Lung 7): a phase 2B, open-label, randomised controlled trial. Lancet Oncol 2016; 17: 577-89. 
39 Jänne PA, Yang JC, Kim DW, et al. AZD9291 in EGFR inhibitorresistant non-small-cell lung cancer. N Engl J Med 2015; 372: 1689-99.

40 Sequist LV, Rolfe L, Allen AR. Rociletinib in EGFR-mutated non-small-cell lung cancer. N Engl J Med 2015; 373: 578-79.

41 Jänne PA, Shaw AT, Pereira JR, et al. Selumetinib plus docetaxel for KRAS-mutant advanced non-small-cell lung cancer: a randomised, multicentre, placebo-controlled, phase 2 study. Lancet Oncol 2013; 14: $38-47$.

42 Mazières J, Gandara SR, Leighl NB, et al. Oral MEK1/MEK2 inhibitor trametinib (GSK1120212) in combination with pemetrexed in a phase $1 / 1 \mathrm{~B}$ trial involving KRAS-mutant and wild-type (WT) advanced non-small cell lung cancer (NSCLC): efficacy and biomarker results. J Thorac Oncol 2013; 8: 2922.

43 Marchetti A, Felicioni L, Malatesta S, et al. Clinical features and outcome of patients with non-small-cell lung cancer harboring BRAF mutations. J Clin Oncol 2011; 29: 3574-79.

44 Paik PK, Arcila ME, Fara M, et al. Clinical characteristics of patients with lung adenocarcinomas harboring BRAF mutations. J Clin Oncol 2011; 29: 2046-51.

45 Hyman DM, Puzanov I, Subbiah V, et al. Vemurafenib in multiple nonmelanoma cancers with BRAF V600 mutations. $N$ Engl J Med 2015; 373: 726-36.

46 Planchard D, Kim TM, Mazieres J, et al. Dabrafenib in patients with BRAFV600E -positive advanced non-small-cell lung cancer: a single-arm, multicentre, open-label, phase 2 trial. Lancet Oncol 2016; 17: 642-50.

47 Mazières J, Peters S, Lepage B, et al. Lung cancer that harbors an HER2 mutation: epidemiologic characteristics and therapeutic perspectives. J Clin Oncol 2013; 31: 1997-2003.

48 Kris MG, Camidge DR, Giaccone G, et al. Targeting HER2 aberrations as actionable drivers in lung cancers: phase II trial of the pan-HER tyrosine kinase inhibitor dacomitinib in patients with HER2-mutant or amplified tumors. Ann Oncol 2015; 26: 1421-27.

49 Sadiq AA, Salgia R. MET as a possible target for non-small-cell lung cancer. J Clin Oncol 2013; 31: 1089-96.

50 Paik PK, Drilon A, Fan PD, et al. Response to MET inhibitors in patients with stage IV lung adenocarcinomas harboring MET mutations causing exon 14 skipping. Cancer Discov 2015; 5: 842-49.

51 Shaw AT, Yeap BY, Mino-Kenudson M, et al. Clinical features and outcome of patients with non-small-cell lung cancer who harbor EML4-ALK. J Clin Oncol 2009; 27: 4247-53.

52 Katayama R, Lovly CM, Shaw AT. Therapeutic targeting of anaplastic lymphoma kinase in lung cancer: a paradigm for precision cancer medicine. Clin Cancer Res 2015; 21: 2227-35.

53 Gainor JF, Varghese AM, Ou SH, et al. ALK rearrangements are mutually exclusive with mutations in EGFR or KRAS: an analysis of 1,683 patients with non-small cell lung cancer. Clin Cancer Res 2013; 19: 4273-81.

54 Shaw AT, Kim DW, Nakagawa K, et al. Crizotinib versus chemotherapy in advanced ALK-positive lung cancer. N Engl J Med 2013; 368: 2385-94.

55 Solomon BJ, Mok T, Kim DW, et al. Firstline crizotinib versus chemotherapy in ALK-positive lung cancer. N Engl J Med 2014; 371: 2167-77.

56 Shaw AT, Kim DW, Mehra R, et al. Ceritinib in ALK-rearranged non-small-cell lung cancer. N Engl J Med 2014; 370: 1189-97.

57 Gadgeel SM, Gandhi L, Riely GJ, et al. Safety and activity of alectinib against systemic disease and brain metastases in patients with crizotinib-resistant ALK-rearranged non-small-cell lung cancer (AF-002JG): results from the dose-finding portion of a phase $1 / 2$ study. Lancet Oncol 2014; 15: 1119-28.

58 Gettinger S, Bazhenova L, Salgia R, et al. ALK Inhibitor AP26113 in patients with advanced malignancies, including ALK+ non-small cell lung cancer (NSCLC): updated efficacy and safety data. Ann Oncol 2014; 25: iv426-70.

59 Zou HY, Li Q, Engstrom LD, et al. PF-06463922 is a potent and selective next-generation ROS1/ALK inhibitor capable of blocking crizotinib-resistant ROS1 mutations. Proc Natl Acad Sci USA 2015; 112: 3493-98.

60 Bergethon K, Shaw AT, Ou SH, et al. ROS1 rearrangements define a unique molecular class of lung cancers. J Clin Oncol 2012; 30: 863-70.
61 Shaw AT, Ou SH, Bang YJ, et al. Crizotinib in ROS1-rearranged non-small-cell lung cancer. N Engl J Med 2014; 371: 1963-71.

62 Boyle TA, Masago K, Ellison KE, Yatabe Y, Hirsch FR. ROS1 immunohistochemistry among major genotypes of non-small-cell lung cancer. Clin Lung Cancer 2015, 16: 106-11.

63 Mazières J, Zalcman G, Crinò L, et al. Crizotinib therapy for advanced lung adenocarcinoma and a ROS1 rearrangement: results from the EUROS1 cohort. J Clin Oncol 2015; 33: 992-99.

64 Awad MM, Katayama R, McTigue M, et al. Acquired resistance to crizotinib from a mutation in CD74-ROS1. N Engl J Med 2013; 368: 2395-401.

65 Rolfo C, Passiglia F, Castiglia M, et al. ALK and crizotinib: after the honeymoon...what else? Resistance mechanisms and new therapies to overcome it. Transl Lung Cancer Res 2014; 3: 250-61.

66 Califano R, Abidin A, Tariq NU, Economopoulou P, Metro G, Mountzios G. Beyond EGFR and ALK inhibition: unravelling and exploiting novel genetic alterations in advanced non small-cell lung cancer. Cancer Treat Rev 2015; 41: 401-11.

67 Drilon A, Wang L, Hasanovic A, et al. Response to cabozantinib in patients with RET fusion-positive lung adenocarcinomas. Cancer Discov 2013; 3: 630-35.

68 Drilon A, Sima CS, Somwar R, et al. Phase II study of cabozantinib for patients with advanced RET-rearranged lung cancers. J Clin Oncol 2015; 33: 8007 (abstr).

69 Doebele RC, Davis LE, Vaishnavi A, et al. An oncogenic NTRK fusion in a patient with soft-tissue sarcoma with response to the tropomyosin-related kinase inhibitor LOXO-101. Cancer Discov 2015; 5: 1049-57.

70 Camidge DR, Ou SD, Shapiro G, et al. Efficacy and safety of crizotinib in patients with advanced c-MET-amplified non-small cell lung cancer (NSCLC). J Clin Oncol 2014; 32: 8001 (abstr).

71 Shigematsu H, Lin L, Takahashi T, et al. Clinical and biological features associated with epidermal growth factor receptor gene mutations in lung cancers. J Natl Cancer Inst 2005; 97: 339-46.

72 Mitsudomi T, Morita S, Yatabe Y, et al. Gefitinib versus cisplatin plus docetaxel in patients with non-small-cell lung cancer harbouring mutations of the epidermal growth factor receptor (WJTOG3405): an open label, randomised phase 3 trial. Lancet Oncol 2010; 11: 121-28.

73 Sequist LV, Yang JC, Yamamoto N, et al. Phase III study of afatinib or cisplatin plus pemetrexed in patients with metastatic lung adenocarcinoma with EGFR mutations. J Clin Oncol 2013; 31: 3327-34.

74 Wu Y-L, Zhou C, Liam CK, et al. First-line erlotinib versus gemcitabine/cisplatin in patients with advanced EGFR mutation-positive non-small-cell lung cancer: analyses from the phase III, randomized, open-label, ENSURE study. Ann Oncol 2015; 26: 1883-89.

75 Yang JC, Sequist LV, Geater SL, et al. Clinical activity of afatinib in patients with advanced non-small-cell lung cancer harbouring uncommon EGFR mutations: a combined post-hoc analysis of LUXLung 2, LUX-Lung 3, and LUX-Lung 6. Lancet Oncol 2015; 16: 830-38.

76 Sequist LV, Waltman BA, Dias-Santagata D, et al. Genotypic and histological evolution of lung cancers acquiring resistance to EGFR inhibitors. Sci Transl Med 2011; 3: 75ra26.

77 Piotrowska Z, Niederst MJ, Karlovich CA, et al. Heterogeneity underlies the emergence of EGFRT790 wild-type clones following treatment of T790M-positive cancers with a third-generation EGFR inhibitor. Cancer Discov 2015; 5: 713-22.

78 Park K, Lee JS, Lee KH, et al. Updated safety and efficacy results from phase I/II study of HM61713 in patients (pts) with EGFR mutation positive non-small cell lung cancer (NSCLC) who failed previous EGFRtyrosine kinase inhibitor (TKI). J Clin Oncol 2015; 33: 8084 (abstr).

79 Yang JJ, Chen HJ, Yan HH, et al. Clinical modes of EGFR tyrosine kinase inhibitor failure and subsequent management in advanced non-small cell lung cancer. Lung Cancer 2013; 79: 33-39.

80 Weickhardt AJ, Scheier B, Burke JM, et al. Local ablative therapy of oligoprogressive disease prolongs disease control by tyrosine kinase inhibitors in oncogene-addicted non-small-cell lung cancer. J Thorac Oncol 2012; 7: 1807-14.

81 Park K, Yu CJ, Kim SW, et al. First-line erlotinib therapy until and beyond response evaluation criteria in solid tumors progression in Asian patients with epidermal growth factor receptor mutation-positive non-small-cell lung cancer: the ASPIRATION study. JAMA Oncol 2016; 2: 305-12. 
82 Soria JC, Wu Y-L, Nakagawa K, et al. Gefitinib plus chemotherapy versus placebo plus chemotherapy in EGFR-mutation-positive non-small-cell lung cancer after progression on first-line gefitinib (IMPRESS): a phase 3 randomised trial. Lancet Oncol 2015; 16: 990-98.

83 Thress KS, Paweletz CP, Felip E, et al. Acquired EGFR C797S mutation mediates resistance to AZD9291 in non-small cell lung cancer harboring EGFR T790M. Nat Med 2015; 21: 560-62.

84 Ercan D, Choi HG, Yun CH, et al. EGFR mutations and resistance to irreversible pyrimidine-based EGFR inhibitors. Clin Cancer Res 2015; 21: 3913-23.

85 Mok T, Wu Y-L, Lee JS, et al. Detection and dynamic changes of EGFR mutations from circulating tumor DNA as a predictor of survival outcomes in NSCLC patients treated with first-line intercalated erlotinib and chemotherapy. Clin Cancer Res 2015; 21: 3196-203.

86 Oxnard GR, Paweletz CP, Kuang Y, et al. Noninvasive detection of response and resistance in EGFR-mutant lung cancer using quantitative next-generation genotyping of cell-free plasma DNA. Clin Cancer Res 2014; 20: 1698-705.

87 Karachaliou N, Mayo-de las Casas C, Queralt C, et al. Association of EGFR L858R mutation in circulating free DNA with survival in the EURTAC trial. JAMA Oncol 2015; 1: 149-57.

88 Wu Y-L, Lee JS, Thongprasert S, et al. Intercalated combination of chemotherapy and erlotinib for patients with advanced stage non-small-cell lung cancer (FASTACT-2): a randomised, double-blind trial. Lancet Oncol 2013; 14: 777-86.

89 Seto T, Kato T, Nishio M, et al. Erlotinib alone or with bevacizumab as first-line therapy in patients with advanced non-squamous non-small-cell lung cancer harbouring EGFR mutations (JO25567): an open-label, randomised, multicentre, phase 2 study. Lancet Oncol 2014; 15: 1236-44.

90 Stahel RA, Dafni U, Gautschi O, et al. A phase II trial of erlotinib (E) and bevacizumab (B) in patients with advanced non-small-cell lung cancer (NSCLC) with activating epidermal growth factor receptor (EGFR) mutations with and without T790M mutation. The Spanish Lung Cancer Group (SLCG) and the European Thoracic Oncology Platform (ETOP) BELIEF trial. Eur J Cancer 2015; 51: S711-12.

91 Zeng Q, Wang J, Cheng Z, et al. Discovery and evaluation of clinical candidate AZD3759, a potent, oral active, central nervous system-penetrant, epidermal growth factor receptor tyrosine kinase inhibitor. J Med Chem 2015; 58: 8200-15.

92 Soda M, Choi YL, Enomoto M, et al. Identification of the transforming EML4-ALK fusion gene in non-small-cell lung cancer. Nature 2007; 448: 561-66.

93 Rikova K, Guo A, Zeng Q, et al. Global survey of phosphotyrosine signaling identifies oncogenic kinases in lung cancer. Cell 2007; 131: 1190-203.

94 Kwak EL, Bang YJ, Camidge DR, et al. Anaplastic lymphoma kinase inhibition in non-small-cell lung cancer. N Engl J Med 2010; 363: 1693-703.

95 Camidge DR, Bang YJ, Kwak EL, et al. Activity and safety of crizotinib in patients with ALK-positive non-small-cell lung cancer: updated results from a phase 1 study. Lancet Oncol 2012; 13: 1011-19.

96 Kim D-W, Ahn M-J, Shi Y, et al: Results of a global phase II study with crizotinib in advanced ALK-positive non-small cell lung cancer. J Clin Oncol 2012; 30: 7533 (abstr).

97 Costa DB, Shaw AT, Ou SH, et al. Clinical experience with crizotinib in patients with advanced ALK-rearranged nonsmall-cell lung cancer and brain metastases. J Clin Oncol 2015; 33: 1881-88.

98 Doebele RC, Pilling AB, Aisner DL, et al. Mechanisms of resistance to crizotinib in patients with ALK gene rearranged non-small cell lung cancer. Clin Cancer Res 2012; 18: 1472-82.

99 Friboulet L, Li N, Katayama R, et al. The ALK inhibitor ceritinib overcomes crizotinib resistance in non-small cell lung cancer. Cancer Discov 2014; 4: 662-73.

100 Mok T, Spigel D, Felip E, et al. ASCEND-2: A single-arm, openlabel, multicenter phase II study of ceritinib in adult patients (pts) with ALK-rearranged (ALK+) non-small cell lung cancer (NSCLC) previously treated with chemotherapy and crizotinib (CRZ) J Clin Oncol 2015; 33: 8059 (abstr).

101 Shaw AT, Gandhi L, Gadgeel S, et al. Alectinib in ALK-positive, crizotinib-resistant, non-small-cell lung cancer: a single-group, multicentre, phase 2 trial. Lancet Oncol 2016; 17: 234-42.
102 Felip E, Orlov S, Park K, et al. ASCEND-3: A single-arm, open-label, multicenter phase II study of ceritinib in ALKi-naïve adult patients (pts) with ALK-rearranged (ALK+) non-small cell lung cancer (NSCLC). J Clin Oncol. 2015; 33: 8060 (abstr).

103 Seto T, Kiura K, Nishio M, et al. CH5424802 (RO5424802) for patients with ALK-rearranged advanced non-small-cell lung cancer (AF-001JP study): a single-arm, open-label, phase 1-2 study. Lancet Oncol 2013; 14: 590-98.

104 Nokihara H, Hida T, Kondo M, et al. Alectinib (ALC) versus crizotinib (CRZ) in ALK-inhibitor naive ALK-positive non-small cell lung cancer (ALK+ NSCLC): Primary results from the J-ALEX study. J Clin Oncol 2016; 34: 9008 (abstr)

105 Wang R, Hu H, Pan Y, et al. RET fusions define a unique molecular and clinicopathologic subtype of non-small-cell lung cancer. J Clin Oncol 2012; 30: 4352-59.

106 Michels S, Scheel AH, Scheffler M, et al. Clinicopathological characteristics of RET rearranged lung cancer in European patients. J Thorac Oncol 2016; 11: 122-27.

107 Scagliotti G, von Pawel J, Novello S, et al. Phase III multinational, randomized, double-blind, placebo-controlled study of tivantinib (ARQ 197) plus erlotinib versus erlotinib alone in previously treated patients with locally advanced or metastatic nonsquamous non-small-cell lung cancer. J Clin Oncol 2015; 33: $2667-74$

108 Spigel DR, Edelman MJ, O’Byrne K, et al. Onartuzumab plus erlotinib versus erlotinib in previously treated stage IIIb or IV NSCLC: Results from the pivotal phase III randomized, multicentre, placebo-controlled METLung (OAM4971g) global trial. J Clin Oncol 2014; 32: 8000 (abstr).

109 Planchard D, Groen HJM, Kim TM, et al. Interim results of a phase II study of the BRAF inhibitor (BRAFi) dabrafenib (D) in combination with the MEK inhibitor trametinib (T) in patients (pts) with BRAFV600E mutated (mut) metastatic non-small cell lung cancer (NSCLC). J Clin Oncol 2015; 33: 8006 (abstr).

110 Dearden S, Stevens J, Wu Y-L, Blowers D. Mutation incidence and coincidence in non small-cell lung cancer: meta-analyses by ethnicity and histology (mutMap). Ann Oncol 2013; 24: 2371-76.

111 Cancer Genome Atlas Research Network. Comprehensive genomic characterization of squamous cell lung cancers. Nature 2012; 489: 519-25.

112 Weiss J, Sos ML, Seidel D, et al. Frequent and focal FGFR1 amplification associates with therapeutically tractable FGFR1 dependency in squamous cell lung cancer. Sci Transl Med 2010; 2: 62 ra93.

113 Hammerman PS, Sos ML, Ramos AH, et al. Mutations in the DDR2 kinase gene identify a novel therapeutic target in squamous cell lung cancer. Cancer Discov 2011; 1: 78-89.

114 Bunn PA Jr, Minna J, Augustyn A, et al. Small cell lung cancer: can recent advances in biology and molecular biology be translated into improved outcomes? J Thorac Oncol 2016; 4: 453-74.

115 Pietanza MC, Byers LA, Minna JD. Small cell lung cancer: will recent progress lead to improved outcomes? Clin Cancer Res 2015 21: $2244-55$

116 Almquist D, Mosalpuria K, Ganti AK. Multimodality therapy for limited-stage small-cell lung cancer. J Oncol Pract 2016; 12: 111-17.

117 Garon EB, Ciuleanu TE, Arrieta O, et al. Ramucirumab plus docetaxel versus placebo plus docetaxel for second-line treatment of stage IV non-small-cell lung cancer after disease progression on platinum-based therapy (REVEL): a multicentre, double-blind, randomised phase 3 trial. Lancet 2014; 384: 665-73.

118 Reck M, Kaiser R, Mellemgaard A, et al. LUME-Lung 1 Study Group. Docetaxel plus nintedanib versus docetaxel plus placebo in patients with previously treated non-small-cell lung cancer (LUME-Lung 1): a phase 3, double-blind, randomised controlled trial. Lancet Oncol 2014; 15: 143-55.

119 Committee for Medicinal Products for Human Use. Summary of opinion: Portrazza. London: European Medicines Agency, Dec 17, 2015 http://www.ema.europa.eu/docs/en_GB/document_library/ Summary_of_opinion_-_Initial_authorisation/human/003886/ WC500199044.pdf (accessed March 6, 2016).

120 Forde PM, Kelly RJ, Brahmer JR. New strategies in lung cancer: translating immunotherapy into clinical practice. Clin Cancer Res 2014; 20: 1067-73. 
121 Vansteenkiste JF, Cho BC, Vanakesa T, et al. Efficacy of the MAGE-A3 cancer immunotherapeutic as adjuvant therapy in patients with resected MAGE-A3-positive non-small-cell lung cancer (MAGRIT): a randomised, double-blind, placebo-controlled, phase 3 trial. Lancet 2016; 17: 822-35.

122 Quoix E, Lena H, Losonczy G, et al. TG4010 immunotherapy and first-line chemotherapy for advanced non-small-cell lung cancer (TIME): results from the phase $2 \mathrm{~b}$ part of a randomised, double-blind, placebo-controlled, phase 2b/3 trial. Lancet Oncol 2016; 17: 212-23.

123 Pardoll DM. The blockade of immune checkpoints in cancer immunotherapy. Nat Rev Cancer 2012; 12: 252-64.

124 Postow M, Callahan MK, Woldchok JD. Immune checkpoint blockade in cancer therapy. J Clin Oncol 2015; 33: 1974-83.

125 Brahmer J, Reckamp KL, Baas P, et al. Nivolumab versus docetaxel in advanced squamous-cell non-small-cell lung cancer. N Engl J Med 2015; 373: 123-35.

126 Borghaei H, Paz-Ares L, Horn L, et al. Nivolumab versus docetaxel in advanced nonsquamous non-small-cell lung cancer. $N$ Engl J Med 2015; 373: 1627-39.

127 Herbst R, Baas P, Kim DW, et al. Pembrolizumab versus docetaxel for previously treated, PD-L1-positive, advanced non-small-cell lung cancer (KEYNOTE-010): a randomised controlled trial. Lancet 2015; 387: $1540-50$.

128 Fehrenbacher L, Spira A, Ballinger M, et al. Atezolizumab versus docetaxel for patients with previously treated non-small-cell lung cancer (POPLAR): a multicentre, open-label, phase 2 randomised controlled trial. Lancet 2016; 387: 1837-46.

129 Rizvi N, Brahmer JR, Ou SH, et al. Safety and clinical activity of MEDI4736, an anti-programmed cell death-ligand 1 (PD-L1) antibody, in patients with non-small cell lung cancer (NSCLC). J Clin Oncol 2015; 33: 8032 (abstr).

130 Gulley JL, Spigel D, Chandler JC, et al. Avelumab (MSB0010718C), an anti-PD-L1 antibody, in advanced NSCLC patients: a phase 1b, open-label expansion trial in patients progressing after platinum-based chemotherapy. J Clin Oncol 2015; 33: 8034 (abstr).

131 Gettinger SN, Horn L, Gandhi L, et al. Overall survival and long-term safety of nivolumab (anti-programmed death 1 antibody, BMS-936558, ONO-4538) in patients with previously treated advanced non-small-cell lung cancer. J Clin Oncol 2015; 33: 2004-12.

132 Garon EB, Rizvi NA, Hui R, et al. Pembrolizumab for the treatment of non-small-cell lung cancer. N Engl J Med 2015; 372: 2018-28.

133 Soria JC, Fløtten Ø, Horn L, et al. Efficacy and safety of pembrolizumab (Pembro; MK-3475) for patients (pts) with previously treated advanced non-small cell lung cancer (NSCLC) enrolled in KEYNOTE-001. Ann Oncol 2015; 26: 33LBA (abstr).

134 Herbst RS, Soria JC, Kowanetz M, et al. Predictive correlates of response to the anti-PD-L1 antibody MPDL3280A in cancer patients. Nature 2014; 515: 563-67.

135 Merck's KEYTRUDA (pembrolizumab) demonstrates superior progression-free and overall survival compared to chemotherapy as first-line treatment in patients with advanced non-small cell lung cancer [news release]. Kenilworth, NJ: Merck, June 16, 2016. http://www.mercknewsroom.com/news-release/oncologynewsroom/mercks-keytruda pembrolizumab-demonstratessuperior-progression-free- (accessed June 18, 2016).

136 Kerr KM, Hirsch FR. Programmed Death Ligand 1 immunohistochemistry: friend or foe? Arch Pathol Lab Med 2016; 140: 326-31.

137 Besse B, Johnson M, Janne PA, et al. Phase II, single-arm trial (BIRCH) of atezolizumab as first-line or subsequent therapy for locally advanced or metastatic PD-L1-selected non-small cell lung cancer (NSCLC). Eur J Cancer 2015; 51: S717-18.
138 Antonia SJ, Bendel JC, Taylor MH, et al. Phase I/II study of nivolumab with or without ipilimumab for the treatment of recurrent small cell lung cancer (SCLC): CA209.032. J Clin Oncol 2015; 33: 7503 (abstr).

139 Alley EW, Schellens JH, Santoro A, et al. Single-agent pembrolizumab for patients with malignant pleural mesothelioma (MPM). IASLC 16th World Conference on Lung Cancer; Denver, CO, USA; Sept 6-9, 2015. Abstract 3011.

140 Ramalingam SS, Owonikoko TK, Khuri FR. Lung cancer: new biological insights and recent therapeutic advances. CA Cancer J Clin 2011; 61: 91-112.

141 Masters GA, Temin S, Azzoli CG, et al. Systemic therapy for stage iv non-small-cell lung cancer: American Society of Clinical Oncology Clinical Practice Guideline Update. J Clin Oncol 2015; 33: $3488-15$.

142 Ciuleanu T, Brodowicz T, Zielinski C, et al. Maintenance pemetrexed plus best supportive care versus placebo plus best supportive care for non-small-cell lung cancer: a randomised, double-blind, phase 3 study. Lancet 2009; 374: 1432-40.

143 Cappuzzo F, Ciuleanu T, Stelmakh L, et al. Erlotinib as maintenance treatment in advanced non-small-cell lung cancer a multicentre, randomised, placebo-controlled phase 3 study. Lancet Oncol 2010; 11: 521-29.

144 Paz-Ares LG, de Marinis F, Dediu M, et al. PARAMOUNT: final overall survival results of the phase III study of maintenance pemetrexed versus placebo immediately after induction treatment with pemetrexed plus cisplatin for advanced non-squamous non-small-cell lung cancer. J Clin Oncol 2013; 31: 2895-902.

145 Westeel V, Quoix E, Moro-Sibilot D, et al. Randomized study of maintenance vinorelbine in responders with advanced non-small-cell lung cancer. J Natl Cancer Inst 2005; 97: 499-506.

146 Fidias PM, Dakhil SR, Lyss AP, et al. Phase III study of immediate compared with delayed docetaxel after front-line therapy with gemcitabine plus carboplatin in advanced non-small-cell lung cancer. J Clin Oncol 2009; 27: 591-98.

147 Brodowicz T, Krzakowski M, Zwitter M, et al. Cisplatin and gemcitabine first-line chemotherapy followed by maintenance gemcitabine or best supportive care in advanced non-small cell lung cancer: a phase III trial. Lung Cancer 2006; 52: 155-63.

148 Belani CP, Waterhouse DM, Ghazal HH, et al. Randomized trial of gemcitabine-carboplatin ( $\mathrm{G}-\mathrm{Cb})$ therapy followed by gemcitabine (G) maintenance or best supportive care (BSC) in advanced NSCLC J Clin Oncol 2010; 28: 7506 (abstr).

149 Perol M, Chouaid C, Perol D, et al. Randomized, phase III study of gemcitabine or erlotinib maintenance therapy versus observation, with predefined second-line treatment, after cisplatin-gemcitabine induction chemotherapy in advanced non-small-cell lung cancer. J Clin Oncol 2012; 30: 3516-24.

150 Zhang X, Zang J, Xu J, et al. Maintenance therapy with continuous or switch strategy in advanced non-small cell lung cancer: a systematic review and meta-analysis. Chest 2011; 140: 117-26.

151 Behera M, Owonikoko TK, Chen Z, et al. Single agent maintenance therapy for advanced stage non-small cell lung cancer: a meta-analysis. Lung Cancer 2012; 77: 331-38.

152 Zhao H, Fan Y, Ma S, et al. Final overall survival results from a phase III, randomized, placebo-controlled, parallel-group study of gefitinib versus placebo as maintenance therapy in patients with locally advanced or metastatic non-small-cell lung cancer (INFORM; C-TONG 0804). J Thorac Oncol 2015; 10: 655-64. 